\title{
FAKTOR PENDORONG DAN PENGHAMBAT RANTAI PASOKAN RAMAH LINGKUNGAN: LITERATUR REVIEW
}

\author{
Anjar Priyono \\ Jurusan Manajemen FE UII \\ e-mail:anjar_priyono@yahoo.com
}

\begin{abstract}
This paper discusses the implementation of green supply chain management in manufacturing industry. Majority of manufacturing companies adopt these practices partially in certain function of organization. This paper describes integration of the whole organization function in the GSCM. Each part plays different role using different methods and techniques. Several elements involved in the product flows are inbound logistic, production function, outbound logistic, and reverse logistic. The last function will be described in detailed explanation since such function is still relatively new. Discussion not only describes the advantage of GSCM implementation but also barriers to implement GSCM. Besides, various cost related to such practices will also be discussed because over cost will have potential negative effect to organization performance. In the last section, controversial issues related to GSCM will be discussed especially how these practices effects organizational performance, how to implement these program in small and medium business, and how the program effect customer preference and customer satisfaction.
\end{abstract}

Key words: supply chain management, inbound logistic, production function, outbound logistic and reverse logistic.

\section{PENDAHULUAN}

Isu rantai pasokan ramah lingkungan dipandang kritis bagi kesuksesan implementasi ekosistem industrial dan ekologi industrial (industrial ecosystem and industrial ecology). Limbah dan emisi yang dikeluarkan oleh rantai pasokan telah menjadi sumber utama maslaah lingkungan termasuk diantaranya pemanasan global dan hujan asam (Bloemhof-Ruward et al., 1995). Perusahaan memiliki beragam alasan untuk menerapkan rantai pasokan ramah lingkungan, mulai dari sekedar kebijakan yang bersifat reaktif hingga pendekatan yang bersifat proaktif untuk mendapatkan keunggulan kompetitif. Dari sudut pandang organisasi ramah lingkungan, sangat penting untuk memahami situasi dan isu apa saja yang muncul dalam bidang manajemen ramah lingkungan ini.
Karena rantai pasokan merupakan suatu sistem yang integratif, maka diperlukan pembahasan yang menyeluruh terhadap seluruh komponen yang terlibat dalam rantai pasokan dengan mempertimbangkan permintaan dan penawaran (Welford et al. (1997). Dengan pertimbangan ini, maka dalam penerapan rantai pasokan ramah lingkungan tidak hanya saja mempertimbangkan proses yang terjadi di dalam perusahaan, tetapi juga yang terjadi di luar perusahaan. Secara kesuluruhan, komponen rantai pasokan ini adalah fungsi pembelian, inbound logistic, produksi, distribusi yang meliputi outbound logistic dan pemasaran, dan reverse logistic. Mayoritas perusahaan masih memfokuskan dirinya pada aktifitasaktifitas yang berada dalam perusahaan, yaitu purchasing, in-bound logistic, dan produksi. Hal ini dapat dimengerti meng- 
ingat ketiga elemen rantai pasokan yang popular dengan value chain concept (Porter, 1985) ini masih berada dalam internal organisasi sehingga lebih mudah untuk dilakukan pengendalian.

Elemen yang terakhir, yaitu reverse logistic merupakan komponen yang relatif jarang tersedia dalam rantai pasokan. Elemen ini membahas bagaimana aliran produk arahnya berlawanan dengan arah pergerakan produk yang pada umumnya berawal dari perusahaan menuju pelanggan. Produk-produk daur ulang bergerak dari pelanggan kepada produsen. Aliran ini sangat berbeda dengan aliran produk yang pada umumnya bergerak dari produsen menuju kepada pelanggan. Gambar 1 mendiskripsikan bagaimana komponenkomponen tersebut menyusun rantai pasokan yang akan dibahas pada bagian berikutnya.

Gambar 1 menujukkan bahwa isu-isu operasional dan isu-isu lingkungan yang biasa muncul dalam rantai pasokan. Fokus utama dari gambar ini adalah bagaimana pengelolaan aliran material agar dapat mengalir dengan lancara dan bagaimana pola hubungan diantara berbagai macam fungsi tersebut. Dalam gambar tersebut dideskripsikan bagaimana vendor yang memiliki rantai pasokanya sendiri baik secara internal maupun eksternal dapat memberikan penawaran material yang diperlukan. Material ini dapat berupa bahan mentah, komponen dari pabrikan, atau recycled material, reusable material atau remanufactured material. Pada bagian ini, terdapat beragam implikasi tergantung fokus aktifitas akuisisinya. Material tersebut ditransfer dari berbagai vendor, yang juga dapat menjadi penentu bagaimana dampak lingkungan produk atau material yang diproduksi. Desain produk dan proses memberikan dampak yang beragam terhadap masing-masing fungsi. Dampak ini perlu dikelola oleh seluruh komponen rantai pasokan yang terdiri dari beragam fungsi. Termasuk dalam isu desain ini diantaranya adalah analisis daur hidup produk dan desain konsep ramah lingkungan.

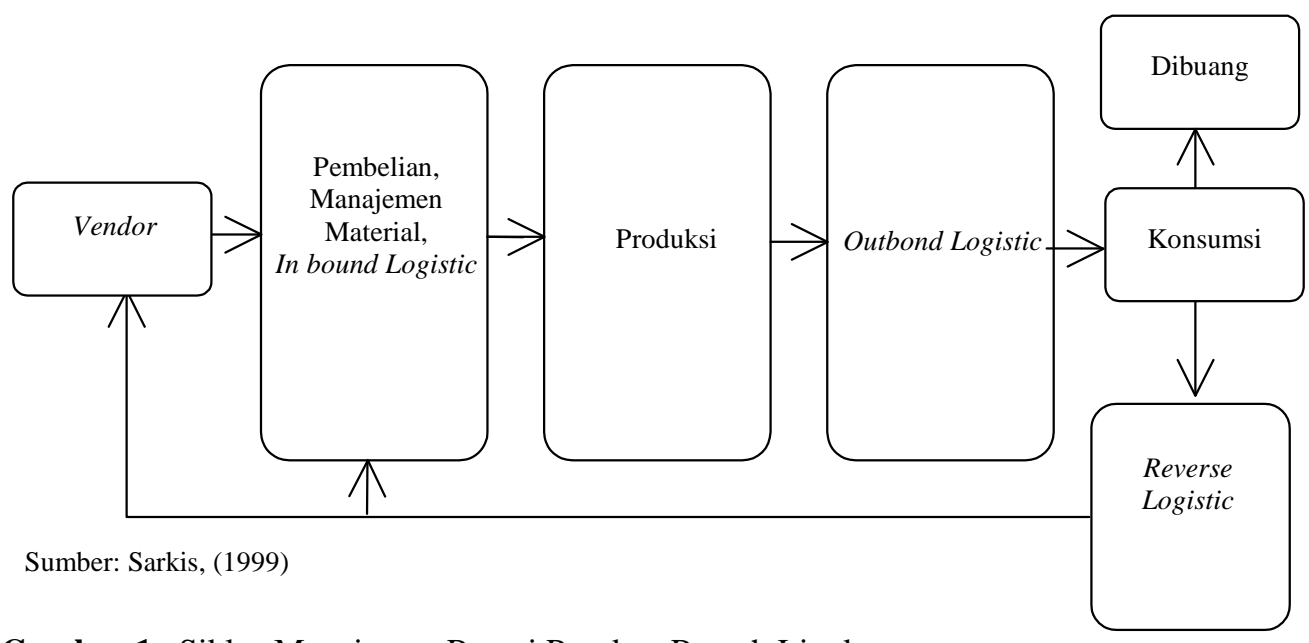

Gambar 1. Siklus Manajemen Rantai Pasokan Ramah Lingkungan 
FUNGSI PEMBELIAN (PURCHASING FUNCTION)

Fungsi pembelian bertanggung jawab terhadap pengadaan barang untuk kepentingan produksi. Tugas yang diemban mencakup pemilihan vendor, pemilihan material, outsourcing, negosiasi, pembelian, penjadwalan pengiriman, manajemen bahan baku dan persediaan, dan pada taraf tertentu juga terlibat dalam pendesainan produk.

Mayoritas perusahaan hanya mampu mengendalikan proses internal organisasi agar tetap ramah lingkungan dan peran vendor kurang mendapatkan perhatian. Sebagian besar perusahaan belum mampu menerapkan kebijakan agar vendor yang menjadi mitra perusahaan mereka juga memiliki kebijakan ramah lingkungan. Dalam menyeleksi vendor ini, manajer pembelian relatif lebih menyukai pengukuran yang bersifat reaktif, misalnya keterbukaan terhadap publik, kandungan limbah berbahanya.

Salah satu metode paling mudah untuk menjamin bahwa vendor telah menerapkan kebijakan ramah lingkungan adalah melalui sertifikasi, khususnya ISO 14001. Sertifikasi ini sangat tepat bagi perusahaan yang tidak bersedia untuk melakukan audit lingkungan terhadap vendornya. Tetapi sayangnya jumlah perusahaan yang telah mendapatkan sertifikasi ini jumlahnya masih relatif kecil. Disamping itu, juga terjadi kendala apabila perusahaan yang menjadi vendor berskala kecil. Penerapan sertifikasi terhadap perusahaan yang berskala kecil justru menimbulkan efek negatif (Burton dan Del Rosario, 1997) karena tingginya biaya sertifikasi.

Salah satu isu dalam proses pengiriman dan produksi adalah penerapan just in time (JIT). Praktek ini berperan untuk mengurangi persediaan sehingga mengurangi biaya dan limbah. Praktek ini mengurangi biaya overhead dan sumber daya yang digunakan untuk mengelola persediaan sehingga dalam JIT diterapkan metode small batch. Dengan menerapkan small batch, maka frekuensi pengiriman menjadi lebih sering dan meningkatkan biaya pengiriman dan penggunaan bahan bakar (Wu dan Dunn, 1995). Oleh karenanya, penerapan JIT juga menimbulkan trade-off dalam manajemen ramah lingkungan.

Dalam tahun-tahun terakhir, perusahaan mulai memanfaatkan peran supplier sebagai sumber keunggulan kompetitif perusahaan untuk meningkatkan kinerja perusahaan (Darnal et al., 2008). Perusahaan juga meminta suppliernya untuk lebih inovatif dengan memanfaatkan teknologi terbaru, mengurangi biaya dalam proses desain pengembangan produknya (Handfield, 1999). Dalam beberapa kasus, perusahaan bahkan mengandalkan pada supplier untuk membangun teknologi pemrosesan yang tidak mampu mereka kembangkan sendiri. Konsekuensinya, perusahaan yang bermaksud untuk meminimalkan dampak lingkungan selama proses pendesainan produk harus mengelola hubungan yang semakin kompleks dengan supplier.

\section{Inbound Logistic}

Dari sudut pandang inbound logistic, rantai pasokan ramah lingkungan memiliki berbagai manfaat bagi organisasi diantaranya pengurangan biaya, integrasi supplier dalam pengambilan keputusan untuk mendorong inovasi ramah lingkungan (Bowen et al., 2001). Mayoritas fungsi inbound logistic ramah lingkungan ditujukan untuk merespon pemintaan global terhadap isu-isu lingkungan. Fungsi ini pembelian yang merupakan elemen yang beroperasi sebelum inbound logistic, memberikan manfaat diantaranya pengurangan limbah dan substitusi material dengan material yang lebih ramah lingkungan untuk meminimalkan bahan-bahan berbahaya. Dukungan dan keterlibatan supplier berperan kritis untuk 
mencapai tujuan ini. Oleh karenanya, perusahaan terus berupaya untuk terus mengelola kinerja lingkungan suppliernya untuk menjamin bahwa material dan peralatan yang dipasok oleh mereka diproduksi dengan menggunakan proses yang ramah lingkungan.

Supplier merupakan komponen utama yang menentukan keberhasilan inbound logistic. Min dan Galle (1997) mengeksplorasi “green purchasing” untuk menentukan apakah faktor-faktor kunci yang menjadi dalam pemilihan supplier, kendala, dan hambatan untuk melaksanakan fungsi pembelian ramah lingkungan. Mereka juga menemukan peran fungsi pembelian terhadap pencapaian tujuan organisasi untuk mewujudkan manajemen hijau. Sruoufe (2003) menyusun indikator untuk mengukur kinerja perusahaan dan kinerja supplier. Bukti empiris menunjukkan bahwa fungsi pembelian ramah lingkungan mampu mendukung inbound logistic untuk memperbaiki posisi kompetitif perusahaan, mengurangi risiko dan memperbaiki kinerja perusahaan.

Dalam inbound logistic, penerapan JIT yang menguatamakan kemitraan dengan supplier dan distributor dapat diterapkan. Dengan pola kemitraan, perusahaan tidak perlu sering melakukan evaluasi terhadap kelayakan distributor dan supplier dari segi keramahan lingkungan. Dengan adanya kemitraan pula, peramalan dapat dilakuan dengan lebih baik karena melibatkan pihak eksternal. Peramalan yang lebih baik juga memungkinkan pengiriman dalam setiap batch menjadi lebih optimal.

Penerapan JIT dalam fungsi produksi juga menimbulkan trade-off. Agar lebih optimal untuk menekan biaya dan lebih ramah lingkungan, pengiriman batch harus mencapai volume yang optimal. Menunggu agar batch dalam volume yang optimal memerlukan waktu tunggu sehingga menurunkan manfaat penerapan JIT.

\section{FUNGSI PRODUKSI (PRODUCTIN FUNCTION)}

Fase-fase produksi memiliki peran kritis untuk menjamin bahwa produk yang dihasilkan oleh perusahaan benar-benar ramah lingkungan, pencegahan polusi sejak dari awal proses dilakukan melalui proses proses produksi ramah lingkungan, praktek produksi ramah lingkungan, re-use dan recycling material, minimalisasi penggunaan material, persentase kandungan produk yang dapat didaur ulang ditingkatkan, proses produksi dioptimalkan untuk mengurangi limbah berbahaya, dan pendesainan ulang produk agar lebih ramah lingkungan.

Salah satu praktek yang banyak diterapkan dalam perusahaan untuk mengelola agar perusahaan benar-benar ramah lingkungan adalah penerapan total quality environmental management (TQEM). Tetapi seperti halnya total quality management, sangat sulit untuk mendapatkan definisi yang konkret dan praktek yang jelas dari TQEM. Hal ini disebabkan TQEM adalah sebuah filosofi, dan bukan merupakan teknologi atau alat tertentu.

Closed-loop manufacturing adalah salah satu ukuran internal yang dapat digunakan untuk meningkatkan kinerja lingkungan rantai pasokan. Filosofi zeroemission yang pada prinsipnya hampir sama dengan prinsip zero-defects dalam program TQM, merupakan prinsip dasar closed-loop manufacturing. Closed-loop manufacturing merupakan proses produksi yang tidak memberikan dampak negatif terhadap lingkungan sama sekali (Darnall et al., 2008).

\section{Out-bound Logistic}

Apabila fungsi pembelian dan inbound logistic memfokuskan pada pengelolaan hubungan antara vendor dengan perusahaan, fungsi distribusi dan out-bound logistic menekankan pada hubungan antara perusahaan dengan pelanggan. Pembahasan 
bagian ini akan dimulai dengan pengelolaan hubungan pelanggan yang memmbahas pemasaran ramah lingkungan dan kemudian out-bound logistic.

Hubungan pelanggan sangat dipengaruhi oleh kebijakan pemasaran ramah lingkungan. Darnall et al. (2008) yang mereview berbagai penelitian menyimpulkan bahwa minat pelanggan terhadap produk ramah lingkungan berpengaruh sangat substansial untuk mendorong agar perusahaan menerapkan program ramah lingkungan. Dorongan yang berasal dari pelanggan ini, dikombinasikan dengan peraturan pemerintah, merupakan dua faktor eksternal yang berperan besar untuk mendorong perusahaan agar ramah lingkungan. Berbagai penelitian menemukan bahwa banyak perusahaan menekan suppliernya sedangkan supplier berupaya memenuhi permintaan pelanggan korporat, dan juga pengguna akhir (Lamming dan Hampson, 1998).

Distribusi ramah lingkungan dan hubungan pelanggan masih menimbulkan kontroversi. Apakah kepedulian mereka terhadap produk ramah lingkungan juga mendorong mereka untuk benar-benar melakukan transaksi? Berbagai penelitian menunjukkan bahwa minat mereka ternyata jauh lebih tinggi dibandingkan dengan transaksi yang sesungguhnya. Fakta ini berlaku untuk pasar individu dan juga pasar industri (Yam-tang dan Chang, 1998).

\section{Outbound Logistic Function}

Wu dan Dunn (1995) menemukan beberapa area dalam praktek standar outbound logistic yang memiliki implikasi terhadap fungsi logistik. Desain dan perencanaan jaringan logistik merupakan dua fungsi yang bersifat strategis. Terdapat beberapa trade-off yang muncul terkait outbound logistic ini, diantaranya waktu pengiriman, kemampuan merespon permintaan pasar, kualitas produk, biaya, dan kinerja lingkungan. Perusahaan tidak dapat berkinerja baik pada seluruh dimensi tersebut. Misalnya, agar dapat merespon keinginan pelanggan secara cepat, maka diperlukan volume persediaan yang besar. Akibatnya, biaya persediaan meningkat dan agar produk dapat bertahan lebih lama diperlukan bahan-bahan kimiawi.

Warehousing dan desain pengiriman paket merupakan dua isu penting dalam distribusi dan outbound logistic. Wu dan Dunn (1995) berpendapat bahwa warehousing tidak hanya sekedar memanfaatkan lahan alami tetapi juga menimbulkan limbah dalam rangkaian rantai pasokan.

Standarisasi kontainer yang dapat digunakan beberapa kali, lay out yang tepat, kemudahan untuk mengakses informasi, dapat mengurangi biaya operasional dan lebih ramah lingkungan. Kemasan produk ini merupakan isu yang sensitif diantara perusahaan manufaktur di negara-negara maju. Masih terdapat kontroversi apakah memang kemasan produk yang dapat digunakan beberapa kali memang lebih baik dibandingkan dengan kemasan produk yang hanya dapat digunakan sekali saja. Misalnya, Reeves (1998) yang melakukan 15 studi tidak menemukan adanya keuntungan tertentu karena menggunakan kemasan yang telah digunakan beberapa kali. Preferensi yang lain muncul dengan memilih tidak menggunakan kemasan sama sekali dibandingkan dengan menggunakan kemasan yang digunakan beberapa kali. Kemasan yang digunakan beberapa kali ini untuk produk tertentu mengurangi kadar higienis produk yang justru berdampak negatif.

\section{Reverse Logistic Function}

Reverse logistic merupakan aliran balik material, komponen, dan produk menujuk ke bagian hulu rantai pasokan. Carter dan Ellram (1998) mendefinisikan reverse logistic sebagai gerakan produk yang arahnya berlawanan setelah digunakan, didaur ulang, dibuang, dengan tujuan untuk 
meminimalkan limbah. Reverse logistic ini merupakan aktifitas yang spesifik, memerlukan keahlian dan bukan kompetensi inti mayoritas perusahaan. Akibatnya, mayoritas perusahaan melakukan outsourcing untuk menangani reverse logistic ini. Keterlibatan pihak ketiga ini memberikan berpeluang membuka pesaing baru bagi produsen awal produk apabila perusahaan reverse logistic ini memutuskan untuk melakukan rekondisi (remanufacture) terhadap produk dalam aliran reverse logistic.

Namun demikian, reverse logistic ini bukannya tanpa kendala. Pohlen dan Farris (1992) mengidentifikasi sejumlah isu terkait dengan reverse logistic ini, diantaranya 1) Sebagian besar sistem persediaan tidak dilengkapi dengan fasilitas yang dapat menangani dengan baik pergerakan produk dari hilir ke hulu. Biaya reverse distribution dapat mencapai hingga 9 kali lipat dibandingkan dengan mendistribusikan produk secara normal. 3) Retur produk seringkali tidak dapat dikirimkan melalui sarana transportasi, disimpan, atau didistribusikan seperti halnya pada saluran distribusi normal seperti biasa. Transportasi reverse logistic ini biasanya lebih kompleks yang panjangnya mencapai hingga 14 kali dibandingkan saluran distribusi normal. Diantara berbagai fungsi manajemen ramah lingkungan, survey yang dilakukan oleh Handfield et al. (1997) menemukan elemen reverse logistic merupakan fungsi yang prioritasnya paling rendah diantara seluruh fungsi rantai pasokan. Fakta ini menunjukkan bahwa fungsi ini masih dalam tahap awal pengenalan dan masih memiliki banyak peluang untuk dilakukan perbaikan dimasa mendatang.

Dari segi permodelan, karakter reverse logistic sangat kompleks. Fleischman et al. (1997) mengidentifikasi terdapat dua isu dalam reverse logistic, yaitu perencanaan persediaan dan pengelolaan produksi. Pengelolaan persediaan pada sistem ini relatif lebih sulit karena aliran logistik yang berlawanan arah dengan aliran normal, lebih sulit untuk dilakukan prediksi sehingga memerlukan fleksibilitas kapasitas, peralatan dan juga memerlukan tambahan safety stock untuk mengantisipasi adanya variabilitas dan ketidakpastian. Pengelolaan produksi merupakan satu bidang yang sangat terkait dengan isu demanufacturing. Teknik dan peralatan yang diperlukan untuk disassembly, demanufacturing, perencanaan produksi (production planning) and pengendalian produksi (production controlling) masih dalam tahap prematur.

\section{ISU-ISU DALAM MANAJEMEN RANTAI PASOKAN RAMAH LINGKUNGAN}

Terdapat berbagai isu-isu yang muncul dalam rantai pasokan ramah lingkungan dan bahkan menimbulkan kontroversi. Hal ini dimungkinkan sebab hingga saat ini masih belum banyak terdapat buktibukti empiris dan praktek yang mendukung teori rantai pasokan ramah lingkungan. Beberapa isu yang muncul ini diantaranya adalah kontribusi terhadap daya saing dan penerapan rantai pasokan ramah lingkungan dalam usaha kecil.

\section{Kontribusi terhadap Daya Saing}

Kontribusi terhadap daya saing perusahaan belum menunjukkan adanya bukti yang kuat bahwa rantai pasokan ramah lingkungan memberikan kontribusi yang signifikan terhadap daya saing perusahaan. Penelitian yang dilakukan oleh Rao (2006) dengan menggunakan sample perusahaan ramah lingkungan di kawasan Asia Tenggara menunjukkan bahwa memang ramah lingkungan turut memberikan kontribusi terhadap daya saing. Akan tetapi setelah dilakukan analisis lebih lanjut, tidak ditemukan adany abukti kuat bahwa kepedulian lingkungan memberikan dampak positif terhadap kinerja ekonomi perusahaan. Bukti empiris ini mempertegas hasil penelitian 
sebelumnya yang dilakukan oleh Green et al. (1998). Penelitian-penelitian memberikan hasil yang tidak konsisten dan bervariasi, diantaranya dilakukan oleh Klassen dan McLaughlin (1996), Hart and Ahuja (1995).

\section{Rantai Pasokan dalam Usaha Kecil}

Salah satu isu yang paling penting adalah apakah mungkin menerapkan manajemen ramah lingkungan pada usaha kecil? Survey yang dilakukan oleh Murphy et al. (1996) menunjukkan bahwa perusahaan kecil kurang begitu berminat untuk melaksanakan program ramah lingkungan dibandingkan dengan perusahaan besar. Mereka memiliki sumber daya yang terbatas untuk menerapkan program-program tersebut. Perusahaan-perusahaan besar merasa lebih sensitif untuk melaksanakan kegiatan ramah lingkungan karena publikasi terhadap kegiatan perusahaan besar lebih mudah diekspos oleh publik dibandingkan perusahaan kecil (Ahmed et al., 1998). Namun demikian, bukan berarti perusahaan kecil sama sekali tidak memiliki kesempatan untuk menerapkan kegiatan ramah lingkungan. Perusahaan-perusahaan besar yang menjadikan perusahaan kecil sebagai mitra atau supplier, bersedia memberikan mentoring, bimbingan, dan konsultasi melalui kegiatan kemitraan (Champion, 1998).

Dengan adanya perbedaan karakter antara perusahaan besar dan perusahaan kecil, investigasi terhadap praktek rantai pasokan ramah lingkungan merupakan topik yang menarik untuk dikaji dalam penelitian empiris. Disamping itu, juga perlu dilakukan analisis terhadap faktor penghambat dan faktor pendorong yang dapat memfasilitasi perusahaan kecil agar dapat lebih banyak terlibat dalam kepedulian lingkungan.

\section{DAFTAR PUSTAKA}

Ahmed, N.U., R.V. Montagno, and R.J. Firenze, (1998), “Organizational performance and environmental consciousness: An empirical study.” Mangement Decision. 36 (2): 57-62.

Bloemhuf-Ruwaard, J.M., P. van Beck, L. Hordijk, dan L.N. van Wassenhove, (1995), "Interactions between operational and environmental management.” European Journal of Operational Research. 85 (2): 229243

Bowen, F.E., Cousins, P.D., Lamming, R.C., dan Faruk, A.C., (2001), Horses for courses: Explaining the gap between theory and practice of supply chain, Greener Management International, Autumn, 41-66.

Burton dan Del Rosario, (1997).

Carter, C.R., dan L.M. Ellram, (1998), "Reverse logistics: A review of the literature and framework for future investigation." Journal of Business Logistics. 19(1): 85-102.

Champion, D., (1998), "Briefings from the Editor: Environmental Management - Spreading the Green.” Harvard Business Review. 76 (6): 16-27.

Cox, A., (1999), "Power, value and supply chain management”. Supply Chain Management Review: An International Journal, 4, 167-175.

Darnal, N., G.J. Jolley, dan R. Handfield., (2008), Environmental Management Systems and Green Supply Chain Management: Complementary for Sustainability?, Business Strategy and the Environment, 17 (1), 30-45.

Fleischmann, M., J. Bloemhof-Ruwaard, R. Dekker, E. van der Laan, J.A. van Nunen, dan L.N. Van Wassenhove, (1997), "Quantitative models for reverse logistics: A review.” 
European Journal of Operational Research. 103 (1): 1-17.

Green, K., B. Morton, dan S. New, (1998), "Green purchasing and supply policies: Do they improve companies' environmental performance?” Supply Chain Management. 3 (2): 89-95.

Handfield, R.B., S.V. Walton, L.K. Seegers, dan S.A. Melnyk, (1997), “'Green’ value chain practices in the furniture industry." Journal of Operations Management. 15 ( ): 293-315.

Hanfield, R., Ragatz, G., Monczka, R., dan Peterson, K., (1999), Involving suppliers in new product development. California Management Review, 42, 59-82.

Hart, S.L., dan Ahuja, G., (1996), "Does it pay to be green: An empirical examination of the relationship between emission reduction and firm performance.” Business Strategy and the Environment. 5 (1): 30-37.

Klassen, R. dan C. McClaughlin, (1996), "The impact of environmental management on firm performance." Management Science. 42 (8): 11991214.

Lamming, R., dan J. Hampson, (1996), “The environment as a supply chain management issue.” British Journal of Management. 7 (S): 45-62.

Min, H. dan W.P. Galle, (1997), "Green purchasing strategies: Trends and implications." International Journal of Purchasing and Materials Management. 33 (3):10-17.

Pohlen, T.L. dan M.T. Farris, (1992), "Reverse logistics in plastics recycling.” International Journal of
Physical Distribution \& Logistics Management. 22(7): 35-47.

Porter, M.E., (1985), Competitive Advantage: Creating and Sustaining Superior Performance, New York: The Free Press.

Preuss, L., (2005), Rhetoric and reality of corporate greening: A view from the supply chain management function. Business Strategy and the Environment, 14, 123-139.

Rao, P. dan D. Holt, (2006), Do green supply chains lead to competitiveness and economic performance?. International Journal of Operations and Production Management, 25 (9), 898-916.

Reeves, T., (1998), "Refillable versus single-trip beverage containers: Europe's battle progresses." Paper \& Packaging Analyst. 32 (2): 91-105.

Rao, P. dan D. Holt (2006). "Do green supply chains lead to competitiveness and economic performance?”. International Journal of Operations and Production Management, 25 (9), 898-916

Welford, R., W. Young, dan B. Ytterhus, (1997), "Toward sustainable production and consumption: A conceptual framework.” Working Paper.

Wu, H.J., dan S.C. Dunn, (1995), "Environmentally responsible logistics systems." International Journal of Physical Distribution \& Logistics Management. 25(2): 20-38.

Yam-Tang, E.P.Y., dan R.Y.K. Chan, (1998), "Purchasing behaviours and perceptions of environmentally harmful products." Marketing Intelligence \& Planning. 16(6-7): 356-362. 